\title{
Prophylactic Radiotherapy of Hip Heterotopic Ossification: A Narrative Mini Review
}

\author{
ERIKA GALIETTA ${ }^{1}$, LUCA GAIANI ${ }^{2}$, CLAUDIO GIANNINI $^{3}$, ANDREA SAMBRI ${ }^{4}$, MILLY BUWENGE $^{1}$, \\ GABRIELLA MACCHIA ${ }^{5}$, FRANCESCO DEODATO ${ }^{5}$, SAVINO CILLA $^{6}$, LIDIA STRIGARI ${ }^{7}$, MICHELE FIORE $^{3}$, \\ SILVIA CAMMELLI ${ }^{1}$, MASSIMILIANO DE PAOLIS ${ }^{4 *}$ and ALESSIO GIUSEPPE MORGANTI ${ }^{1 *}$ \\ ${ }^{1}$ Radiation Oncology, IRCCS Azienda Ospedaliero-Universitaria di Bologna, \\ Department of Experimental, Diagnostic and Specialty Medicine-DIMES, \\ Alma Mater Studiorum University of Bologna, Bologna, Italy; \\ ${ }^{2}$ U.O. Ortopedia e Traumatologia, AUSL Imola, Imola, Italy; \\ ${ }^{3}$ IRCCS Istituto Ortopedico Rizzoli, Bologna, Italy; \\ ${ }^{4}$ UOC Ortopedia e Traumatologia, IRCCS Azienda Ospedaliera Universitaria di Bologna, Bologna, Italy; \\ ${ }^{5}$ Radiation Oncology Unit, Gemelli Molise Hospital-Università Cattolica del Sacro Cuore, Campobasso, Italy; \\ ${ }^{6}$ Medical Physics Unit, Gemelli Molise Hospital-Università Cattolica del Sacro Cuore, Campobasso, Italy; \\ ${ }^{7}$ Medical Physics Unit, IRCCS Azienda Ospedaliero-Universitaria di Bologna, Bologna, Italy
}

\begin{abstract}
Evidence on prophylactic radiotherapy $(R T)$ in hip heterotopic ossification $(\mathrm{HO})$ is sparse and conflicting. The aim of this literature review was to collect and summarize the available data on RT efficacy in preventing hip HO. The results of this review show that $R T$ is effective in the prevention of hip $\mathrm{HO}$, albeit with large variability across series. Effective prophylactic $R T$ requires optimal treatment fields and time intervals with surgery. On the contrary, there is no clear evidence on the optimal timing (post-operative versus pre-operative RT). Comparisons between prophylactic $R T$ and use of non-steroidal antiinflammatory drugs showed conflicting results, although most were in favor of RT. In conclusion, RT is an established prophylactic treatment for hip HO. However, optimal dose, technique and timing remain unclear, as does the usefulness of combining $R T$ with drugs.
\end{abstract}

This article is freely accessible online.

*These Authors contributed equally to this study.

Correspondence to: Dr. Erika Galietta, MD, Radiation Oncology, IRCCS Azienda Ospedaliero-Universitaria di Bologna, DIMES, Alma Mater Studiorum - Bologna University, Via Albertoni 15, 40138 Bologna, Italy. Tel: +39 0512143564, e-mail: erika.galietta@studio.unibo.it

Key Words: Literature review, radiotherapy, prophylaxis, heterotopic ossification, hip, review.
Heterotopic ossification (HO) is defined as the formation of new bone in soft tissue outside the skeletal system (1). HO can be differentiated into three main groups: traumatic $\mathrm{HO}$ (mainly following fractures), non-traumatic HO (usually occurring after burns), and neurological HO (2).

Several prophylactic treatments for HO have been proposed, such as non-steroidal anti-inflammatory drugs (NSAIDs), Noggin (an extracellular peptide that binds and antagonizes bone morphogenetic proteins), pulsed electromagnetic fields, and free radical scavengers (3-11).

$\mathrm{HO}$ is a particularly frequent complication after total hip arthroplasty, with reported rates ranging from $15 \%$ to $90 \%$. In patients with a significant amount of ossification, hip mobility can be impaired (12). Main risk factors for $\mathrm{HO}$ after total hip arthroplasty are male gender, hip ankylosis, and previous history of HO $(13,14)$. The only effective treatment of symptomatic, established $\mathrm{HO}$ is surgical resection (15).

From the early 1980s (16), radiotherapy (RT) has been extensively studied and used in this setting. Most evidence on RT efficacy in preventing hip HO comes from nonrandomized studies (17-45), although some randomized trials (46-61) and systematic-reviews and meta-analyses (62-68) have been performed.

However, evidence on prophylactic RT is sparse and conflicting, no international guidelines are available, and several questions remain unanswered. Therefore, the aim of this literature review was to collect and summarize the main available evidence on RT efficacy in preventing hip HO. 
Table I. Number of patients and main findings of nonrandomized studies.

Ref Authors, year Patients, $n \quad$ Main findings

17

Sylvester et al., 1992

82

18

Moed et al., 1994
Only 6/92 assessable hips treated with postop RT developed HO. Five of these were explained by initiating treatment 5 days after surgery or by a block malposition. Of 78 hips irradiated before postoperative day 6 with adequate shielding, only $1(1.3 \%)$ exhibited HO growth. RT is effective in HO prevention if delivered within 4 days after surgery and when technical aspects are taken into consideration.

The combination of postoperative RT and indomethacin was very effective in $\mathrm{HO}$ prevention: only 10 fractures presented class I HO. RT with 12 Gy in 3 daily doses and 7 Gy in a single fraction led to similarly improved results.

Of the irradiated hips, $6 \%$ exhibited grade II or III HO and $0 \%$ grade IV, while in the control group: $34 \%$ grade II-III and $6 \%$ grade IV HOs were recorded. A progression of $\mathrm{HO}$ was estimated in $30 \%$ of the patients who underwent RT and in $84 \%$ of the control group, with a significant difference considering age and weight $(p<0.001)$. A single 6-Gy postoperative RT dose within the first 3 days after surgery led to effective HO prophylaxis.

HOs developed in 12/19 hips treated with 5.5 Gy and in 9/88 hips treated with $7 \mathrm{~Gy}$. A dose of 5.5 Gy seemed not as effective as 7 Gy dose in prophylaxis of HO after surgery $(p<0.01)$. A single 7-Gy postoperative RT dose is recommended as effective HO prophylaxis.

In patients who underwent RT (75 hips), the mean postoperative HHS was improved (95) while in patients not treated with RT (79 hips) the mean HHS was worse (92). HHS was increased by 11 points in irradiated hips with poor preoperative range of motion. HHS was higher in all patients but not significantly between the two groups (Mann-Whitney test: -0.8373 ). Regarding results with HHS $<80$, these were in two irradiated patients and in 11 unirradiated patients, with a significant risk of reduced HHS in patients not irradiated $(p<0.025)$.

Overall, $1 \%$ of irradiated patients presented Brooker III-IV HOs, while $9 \%$ of non-treated patients had the same HO grades. Male elderly patients with primary arthrosis represent the group with higher $\mathrm{HO}$ risk.

After prosthetic re-implantation, incidence of HOs was $41 \%$ in patients treated with RT $v s$. $61 \%$ in the control group ( $p=0.0328$ ); high-grade HOs occurred in $2 \%$ and $9 \%$, respectively. At radiographic follow-up (6 months after RT) of 47/66 patients, 6 developed grade III HO (4 had received $10 \mathrm{~Gy} / 5$ fractions and 2 received $8 \mathrm{~Gy} / 1$ fraction) while no patient showed grade IV HO ( $p$-value not reported). Within 24 hours of surgery, 7-8 Gy should be delivered in order to prevent $\mathrm{HO}$.

After surgery plus postoperative RT, no different in recurrence rates was observed between different $\mathrm{HO}$ etiologies after 1-year (ossification area: patients with multiple injuries $1.9 \mathrm{~cm}^{2}$, with isolated brain injury, $2.0 \mathrm{~cm}^{2}$, after local hip trauma, $2.1 \mathrm{~cm}^{2}$ ) and 5-year follow-up period (patients with multiple injuries, $2.1 \mathrm{~cm}^{2}$, with isolated brain injury, $2.2 \mathrm{~cm}^{2}$, after local hip trauma, $2.3 \mathrm{~cm}^{2}$ ). Patients after local hip trauma had progressively improved Merle d'Aubigne and Postel score*: preoperative, 7.5; 1-year follow-up, 13; follow-up 5 years, 13.4 points).

Patients treated with $10 \mathrm{~Gy} / 5$ fractions and $8 \mathrm{~Gy} / 1$ fraction postoperative RT who developed grade III-IV HO were $1 / 22$ and $1 / 28$, respectively, nobody between patients treated with indomethacin. Grade I-II HOs were observed in $3 / 25$ of patients in the indomethacin group, in $3 / 28$ of 8 Gy and no one in 10 Gy group. Between the two groups, the distribution of risk factor was significantly different $(p<0.05)$. Indomethacin had the same efficacy as RT in lower risk patients, with reduced costs.

Six patients developed grade I-II HOs 12 months after RT (7.5 Gy preoperatively, within 16 $\mathrm{h}$ before surgery).

After prophylactic RT of 4,377 hips, 475 (11\%) were suspicious for HO on radiographic exams. Functional impairment was recorded in 34/685 (5\%) hips. Outcomes were similar in patients treated with pre- and postoperative RT. However, patients treated $>8 \mathrm{~h}$ before surgery or $>72 \mathrm{~h}$ after surgery had a worse radiological failure rate $(p<0.05)$.

RT delivered the day before surgery is effective in higher grade $\mathrm{HO}$ prevention. The incidence of HO was as follows: any grade $18.1 \%(n=84)$, grade I $12.3 \%(n=57)$, grade II $3.9 \%(n=18)$, grade III $1.5 \%(\mathrm{n}=7)$, and grade IV $0.4 \%(\mathrm{n}=2)$.

Of patients treated with prophylactic RT before surgery, 281 (81.5\%) did not present HO, 58 had grade I-II HO, and six (1.7\%) grade III-IV HO. RT must be used in hip HO prophylaxis. Higher grade $\mathrm{HO}$ affects physical functions. 
Table I. Continued

\begin{tabular}{|c|c|c|c|}
\hline Ref & Authors, year & Patients, $\mathrm{n}$ & Main findings \\
\hline 31 & Roth et al., 2005 & 90 & $\begin{array}{l}\text { Patients with total hip replacement were treated with RT: doses of } 5 \times 3 \text { Gy were delivered in } \\
14 \text { patients between the first and the fifth postoperative day, } 1 \times 7 \text { Gy in } 13 \text { patients within } 24 \\
\text { h after surgery, } 1 \times 7 \text { Gy in } 63 \text { patients within } 24 \mathrm{~h} \text { before the surgery. No significant HOs } \\
\text { were recorded during the follow-up. Time from RT to surgery should be } \leq 24 \mathrm{~h} \text {. RT should } \\
\text { be delivered before surgery in order to reduce logistic problems. }\end{array}$ \\
\hline 32 & Chao et al., 2006 & 124 & $\begin{array}{l}\text { Patients after THA or excision of } \mathrm{HO} \text { underwent } \mathrm{RT} \text { to prevent } \mathrm{HO} \text {. Of patients in follow- } \\
\text { up, } 12.3 \% \text { with ipsilateral } \mathrm{HO} \text { had significant } \mathrm{HO} \text {, while of those with contralateral HO, } \\
10.5 \% \text { had significant } \mathrm{HO} \text { after THA. Patients treated with } 6 \mathrm{~Gy} \text { in } 3 \text { fractions experienced } \\
\text { severe ipsilateral } \mathrm{HO} \text { after surgery in } 60 \% \text { of cases, while only } 13.8 \% \text { of patients who } \\
\text { received } 7 \mathrm{~Gy} \text { in } 1 \text { fraction had severe } \mathrm{HO} \text {, similarly to other regimens. }\end{array}$ \\
\hline 33 & Pakos et al., 2006 & 54 & $\begin{array}{l}\text { After THA and postoperative combined treatment (RT plus indomethacin), the } 1 \text {-year overall } \\
\text { HO rate was } 20.4 \% \text {, with only one patient showing high-grade HO. }\end{array}$ \\
\hline 34 & Balboni et al., 2007 & 137 & $\begin{array}{l}\text { Of } 137 \text { included patients, only } 84 \text { were eligible. Eight out of } 40 \text { patients treated with } \\
\text { unshielded fields had HO vs. } 21 / 44 \text { patients treated with shielded fields }(p=0.009) \text { and } 5 \% \\
\text { of the patients of the first group developed grade III and IV HO, while } 18 \% \text { of patients of } \\
\text { the second had severe HO ( } p=0.08) \text {. Therefore, a higher risk of RT failure was observed in } \\
\text { patients treated with shielded fields. }\end{array}$ \\
\hline 35 & Ince et al., 2007 & 286 & $\begin{array}{l}\text { RT plus short-course indomethacin in HO prophylaxis did not negatively affect the stability } \\
\text { of cementless cups in patients operated for primary THA. }\end{array}$ \\
\hline 36 & Cipriano et al., 2009 & 60 & $\begin{array}{l}\text { Standard RT doses did not reduce neurogenic HO recurrence rates. More HOs were recorded } \\
\text { in the treatment group }(15.0 \%) \text { compared to the control group }(5.1 \%)(p<0.05) ; 7 \text { Gy RT in } \\
\text { a single fraction seems not effective in preventing the recurrence of neurogenic HO in high- } \\
\text { risk patients. }\end{array}$ \\
\hline 37 & Pakos et al., 2009 & 99 & $\begin{array}{l}\text { After 6-months of follow-up, the incidence of } \mathrm{HO} \text { in patients treated with indomethacin alone } \\
\text { was higher }(34.5 \%, 95 \% \mathrm{CI}=22.2-48.6 \%) \text { compared to patients receiving postoperative RT } \\
\text { plus indomethacin }(27.3 \%, 95 \% \mathrm{CI}=15.0-42.8 \%)(p=0.5) \text {. }\end{array}$ \\
\hline 38 & Pakos et al., 2010 & 71 & $\begin{array}{l}\text { After combined RT plus indomethacin, the overall radiographical incidence of } \mathrm{HO} \text { after 1- } \\
\text { year follow-up was } 7.0 \%(95 \% \mathrm{CI}=2.3-15.7) \text { and no high-grade HOs was observed. } \\
\text { Fractionated RT (total of } 10 \mathrm{~Gy} \text { ) was effective as a single } 7 \text {-Gy fraction. }\end{array}$ \\
\hline 39 & Le Duff et al., 2011 & 838 & $\begin{array}{l}\text { Combined indomethacin plus RT is an effective prophylactic treatment: HO rates were } \\
\text { reduced between patients treated with indomethacin and patients receiving indomethacin plus } \\
\text { preoperative ( } 7 \mathrm{~Gy}) \mathrm{RT}(p=0.048) \text {. }\end{array}$ \\
\hline 40 & Weng et al., 2015 & 91 & $\begin{array}{l}\text { In subjects with ankylosing spondylitis there was no difference in } \mathrm{HO} \text { incidence between } \\
\text { patients without postoperative prophylactic RT and patients treated with postoperative single } \\
\text { fraction RT ( } 5 \mathrm{~Gy})(p=0.210) \text {. }\end{array}$ \\
\hline 41 & d'Heurle et al., 2016 & 241 & RT was effective in preventing HOs $(\mathrm{OR}=0.29,95 \% \mathrm{CI}=0.10-0.85)$. \\
\hline 42 & Mourad et al., 2017 & 64 & $\begin{array}{l}\text { Based on dose-volume histograms, mean and maximum dose to the testicles were } 1 \mathrm{~Gy} \text { and } \\
3.1 \mathrm{~Gy} \text {, respectively. Using a split-beam technique, there was a decrease in both: } 44 \% \text { and } \\
47 \% \text {, respectively, and reached } 26 \% \text { and } 14 \% \text {, respectively, using } 10-18 \mathrm{MV} \text { beams. Testicular } \\
\text { shielding should be used in male patients receiving low-dose RT as HO prophylaxis. }\end{array}$ \\
\hline 43 & Müseler et al., 2017 & 444 & $\begin{array}{l}\text { In patients with } \mathrm{HO} \text { following spinal cord injury, no side-effects occurred in patients after } \\
\text { single-fraction RT. Only one patient experienced ankylosis after repeated RT and was } \\
\text { operated on subsequently. }\end{array}$ \\
\hline 44 & Honore et al., 2020 & 95 & $\begin{array}{l}\text { Preoperative RT delivered in } 89.5 \% \text { of cases was not effective when combined with surgery } \\
\text { in patients with significant HO: ORs for recurrence were similar for different groups (total } \\
\text { population, OR=0.63, } 95 \% \mathrm{CI}=0.06-3.27 ; p=0.72) \text {; spinal cord injury subgroup, OR=0.45; } \\
\text { head injury subgroup, OR=1.04). RT appeared to be associated with a higher risk of sepsis } \\
\text { after surgery }(p<0.05) \text {. }\end{array}$ \\
\hline 45 & Pakos et al., 2020 & 97 & $\begin{array}{l}\text { In patients treated with surgery and prophylactic RT, no cases of RT-induced tumors were } \\
\text { observed during the } 10 \text {-year follow-up period. }\end{array}$ \\
\hline
\end{tabular}

HHS: Harris Hip Score, an outcome measure after hip surgery; HO: heterotopic ossification; RT: radiotherapy; THA: total hip arthroplasty. *Based on pure pain, mobility of the leg and ability to walk, grading each from 1 to 6 points.

\section{Review Method}

A literature search was conducted on PubMed on 30 May 2021. The search strategy was as follows: "heterotopic
ossification"[All Fields] AND “hip"[All Fields] AND ("radiotherapy"[All Fields] OR "radiation"[All Fields]). In this review, we included clinical studies and meta-analyses published in English after 1990 reporting on patients treated 
Table II. Number of patients and main findings of randomized trials.

\begin{tabular}{|c|c|c|c|}
\hline Ref & Authors, year & Patients, $\mathrm{n}$ & Treatment arms \\
\hline 46 & Konski et al., 1990 & 47 & $5 \times 10$ Gy $v s .1 \times 8$ Gy \\
\hline 47 & $\begin{array}{l}\text { Seegenschmiedt } \\
\text { et al., } 1993\end{array}$ & 60 & $\begin{array}{l}\text { LD-RT: Arm A=5×2 Gy vs. } \\
\text { HD-RT: Arm B1=10×2 Gy or } \\
\text { Arm B2 }=5 \times 3.5 \text { Gy }\end{array}$ \\
\hline 48 & $\begin{array}{l}\text { Seegenschmiedt } \\
\text { et al., } 1993\end{array}$ & 137 & $\begin{array}{l}\text { LD-RT: } 5 \times 2 \text { Gy } v s . \\
\text { HD-RT: } 10 \times 2 \text { Gy or } 5 \times 3.5 \text { Gy }\end{array}$ \\
\hline 49 & $\begin{array}{c}\text { Gregoritch et al., } \\
1994\end{array}$ & 122 & $\begin{array}{l}\text { Preoperative RT ( }<4 \mathrm{~h} \text { before } \\
\text { surgery) vs. 'standard' } \\
\text { postoperative RT }(<48 \mathrm{~h} \text { after } \\
\text { surgery) schedules }\end{array}$ \\
\hline
\end{tabular}

50 Pellegrini et al., 1996

Knelles et al., 1997 1997

$$
\text { et al., } 1998
$$

14-day indomethacin $v s$.

7-day indomethacin $v s$. irradiation $4 \times 3$ Gy vs. $1 \times 7$ Gy

vs. $1 \times 5$ Gy (in all cases postoperatively) $v s$. control group

Postoperative irradiation $1 \times 5$ Gy vs. $1 \times 7$ Gy vs. NSAIDs

\section{From 1987 to 1992 :}

Postoperative 'low dose' $5 \times 2$ Gy or 'medium dose' $5 \times 3.5$ Gy RT.

From 1992 to 1995 : $1 \times 7$ Gy preoperatively ( $\leq 4 \mathrm{~h})$ or $5 \times 3.5 \mathrm{~Gy}$ postoperatively ( $\leq 96 \mathrm{~h})$

$100 \quad 1 \times 7$ Gy Preoperatively $v s$. NSAID

In preventing $\mathrm{HO}$, RT delivered with single-fraction $8 \mathrm{~Gy}$ is as effective as $10 \mathrm{~Gy}$ in 5 fractions ( $p$-value not reported). Analyzing the differences in radiographic scores soon after surgery and radiographs performed 2 months later, the resulting score was increased in 4 patients ( 1 treated in the 8-Gy arm and 3 in the 10Gy arm). However, no patient showed grade III-IV HO.

Four patients developed treatment failure. Delayed post-operative RT on day 4 after surgery was significantly correlated with treatment failure $(p<0.001)$. No difference was recorded between LD-RT and HD-RT.

RT was effective as prophylactic treatment of HO in 129/137 hips (91.5\%). HD-RT dose combined with NSAID was correlated with a successful result $(p=0.009)$ compared to LD-RT.

Prophylactic RT delivered $\leq 4 \mathrm{~h}$ before surgery was equally effective compared to postoperative RT in preventing clinically significant hip HO. HO rates were 26\% after preoperative RT and $28 \%$ after postoperative RT $(p>0.99)$. Grade III-IV HOs were recorded in $2 \%$ and $5 \%$ of patients treated with preoperative and postoperative RT, respectively.

HOs were observed in 12/49 hips treated with preoperative RT and $3 / 37$ hips treated with postoperative RT $(p=0.05)$. Preoperative RT is effective as prophylactic treatment of postsurgical HO while avoiding discomfort and complications related to the postoperative RT. HO was found in $18.4 \%$ of the hips and no cases of ankylosis occurred. In $4 \times 3$ Gy and $1 \times 7$ Gy RT groups, HO presented as grade $0-\mathrm{I}$, whereas in patients treated with acetylsalicylic acid or $1 \times 5$ Gy RT, higher grade HOs were observed. All treatments showed a significant improvement compared with the control group $(p=0.001)$.

The results suggested that after hip replacement, prophylactic RT with 7 Gy single-fraction is more effective than RT with 5 Gy in single-fraction or NSAID-based treatment. HO rates were $11.1 \%$ $30.1 \%$ and $16.0 \%$ respectively. The difference in HO overall was statistically significant between NSAID and with 5 Gy-RT $(p<0.015)$ and between $7-$ Gy RT and 5-Gy RT $(p<0.0001)$ groups, however no significant difference was observed between NSAID and 7 Gy-RT groups $(p>0.3)$.

15 Progressions were found in the postoperative low-dose group and 7 in the medium-dose group $(p>0.05)$. Comparing $1 \times 7$ Gy preoperatively and $5 \times 3.5$ Gy postoperatively, 11 and 4 cases of $\mathrm{HO}$ were recorded, respectively $(p<0.05)$. Except for a small subset of patients with ipsilateral grade III-IV Brooker, pre- and postoperative RT are equally effective in preventing hip $\mathrm{HO}$ after surgery. HOs were recorded in $47.8 \%$ and in $11.1 \%$ in the 7 Gy preoperative group and in the NSAID group, respectively $(p<0.01)$. However, no difference between the two arms with regard to grade III-IV HO was registered $(p>0.05)$.

Two patients treated with postoperative RT presented grade I HO and 16 patients treated with NSAID had grade I-II HO $(p<0.001)$. Both postoperative RT and NSAID were effective prophylactic treatments. The best results were achieved after RT $(3 \times 3.3 \mathrm{~Gy})$. During a mean follow-up of 2.5 years, HO rates in the control group were higher (16/19) compared to patients treated with $5 \mathrm{~Gy}$ single-fraction RT (6/43) ( $p=0.001)$.

Grade III-IV HO occurred only in patients without postoperative RT or indomethacin, resulting in a statistically significant effect (chi square, $p<0.001)$. Both $\mathrm{RT}$ and indomethacin are effective in preventing $\mathrm{HO}$. 
Table II. Continued

\begin{tabular}{|c|c|c|c|c|}
\hline Ref & Authors, year & Patients, $\mathrm{n}$ & Treatment arms & Main findings \\
\hline 58 & Burd et al., 2001 & 1668 & $\begin{array}{l}8 \text { Gy Within } 72 \mathrm{~h} \text { after surgery } v s \text {. } \\
\text { indomethacin within } 24 \mathrm{~h} \text { after } \\
\text { surgery } v s . \text { no prophylaxis }\end{array}$ & $\begin{array}{l}\text { Grade III-IV HO occurred in } 8 \text { in the indomethacin group and } 3 \text { in } \\
\text { the RT group }(p=0.22) \text {. Furthermore, all } 16 \text { patients who did not } \\
\text { undergo prophylactic therapy had HO ( } 6 \text { grade III-IV). RT and } \\
\text { indomethacin are effective methods of prophylaxis against HO after } \\
\text { surgery. }\end{array}$ \\
\hline 59 & Padgett et al., 2003 & 59 & $\begin{array}{l}\text { Group A: } 2 \times 250 \mathrm{cGy} v s \text {. } \\
\text { Group B: } 5 \times 200 \mathrm{cGy}\end{array}$ & $\begin{array}{l}\text { The difference in terms of HO distribution in the two groups was } \\
\text { not statistically significant }(p=0.086) \text {. The success rates after } 5 \text { Gy } \\
(2 \times 250 \text { cGy }) \text { and } 10 \text { Gy }(5 \times 200 \text { cGy) postoperative RT were } 93 \% \\
\text { and } 97 \% \text {, respectively. RT delivered with } 5 \text { Gy dose is effective in } \\
\text { HO prophylaxis. }\end{array}$ \\
\hline 60 & Pakos et al., 2009 & 96 & $\begin{array}{l}\text { Postoperative RT of } 1 \times 7 \mathrm{~Gy} \\
\text { and indomethacin } v s . \\
\text { indomethacin alone }\end{array}$ & $\begin{array}{l}\text { HO was found in } 4 \text { patients treated with } 7 \text { Gy single-fraction } \\
\text { postoperative RT, in } 13 \text { in the indomethacin group }(p<0.05) \text { and } 13 \\
\text { in a historical group }(p<0.05) \text {. One patient with grade III HO was } \\
\text { recorded both in the combined treatment group and in the historical } \\
\text { group. RT plus indomethacin was more effective in HO prophylaxis } \\
\text { compared to indomethacin alone. }\end{array}$ \\
\hline 61 & Z Liu et al., 2017 & 147 & $\begin{array}{c}\text { Postoperative RT: } 1 \times 4 \mathrm{~Gy} \\
\text { vs. } 1 \times 7 \mathrm{~Gy}\end{array}$ & $\begin{array}{l}\text { HOs were detected on radiographs in } 42 \% \text { and } 25 \% \text { of patients } \\
\text { treated with } 4 \text { Gy and } 7 \text { Gy, respectively }(p=0.035) \text {. RT delivered } \\
\text { as } 7 \text {-Gy single-fraction was more effective than } 4 \text {-Gy single fraction } \\
\text { in HO prophylaxis. }\end{array}$ \\
\hline
\end{tabular}

HO: Heterotopic ossification; LD-/HD-RT: low-dose/high-dose radiotherapy; NSAID: non-steroidal anti-inflammatory drug.

with RT to prevent hip HO development, including results in terms of efficacy or toxicity, with data on RT dose and fractionation, with prospective or retrospective design, and enrolling more than 50 patients. Studies were excluded in the case of their being a letter, commentary, editorial, case report, conference proceedings, reports on study protocols, preclinical studies, studies on animal models, imaging or planning studies, surveys, guidelines, or recommendations, or due to inclusion of prophylactic RT for sites other than the hip, or duplication of data.

A summary of the main findings of selected nonrandomized studies, randomized trials, and meta-analyses are summarized in Table I, Table II, and Table III, respectively. Figure 1 shows computed tomographic scans of an extensive $\mathrm{HO}$ of the right hip of a 55-year-old male patient with paralysis of the lower extremity.

\section{Discussion}

All studies on the efficacy of RT in the prevention of hip HO reported a significant advantage over surgery alone $(19,22,23$, $41,56,57)$. However, the incidence of $\mathrm{HO}$ after prophylactic RT was highly variable, with overall rates ranging between $6 \%$ and $28 \%(17,19,27,29,30,46,49)$, and grade III-IV HO rates ranging from $0 \%$ to $5 \%(19,24,27,29,30,46,49,57)$. Nevertheless, no grade III-IV hip HO cases were recorded in most series of patients treated with RT $(19,24,27,46,57)$.

In terms of dose, many studies analyzed the impact of RT regimens on $\mathrm{HO}$ rates $(18,20,26,32,38,46,48,51,52,59$,
61, 65-67). In some studies, single 7- to 8-Gy fractions were found to be equivalent to regimens of $3 \times 4 \mathrm{~Gy}(18)$ and $5 \times 2$ Gy $(26,38,46)$. Furthermore, other studies have shown the superiority of $1 \times 7$ Gy over regimens of $1 \times 4$ Gy (61), 1×5 Gy $(51,52), 1 \times 5.5$ Gy $(20)$, and $3 \times 2$ Gy (32). Moreover, some analyses reported the equivalence of $5 \times 2$ Gy versus $1 \times 7$ Gy (38), $1 \times 8$ Gy (46), 10×2 Gy (48), 5×3.5 Gy (48), and $2 \times 2.5$ Gy (59). In addition, one study showed the greater efficacy of $4 \times 3$ Gy compared to $1 \times 5$ Gy (51). Finally, two meta-analyses did not record a significant impact of RT dose on postoperative $\mathrm{HO}$ incidence $(64,65)$, while another showed an advantage of multi-fractionated RT over single-fraction RT (67).

In terms of the timing between surgery and prophylactic RT, some studies reported superior results in patients with an interval of less than 6 days (17), and 3 days $(19,28)$. Furthermore, another study confirmed that delays in postoperative RT can reduce its efficacy in terms of $\mathrm{HO}$ prophylaxis (47). Finally, a study showed that the effectiveness of preoperative RT is greater in the case of an RT-surgery interval $\leq 8$ hours (28).

Comparing pre- versus post-operative prophylactic RT, three studies did not show significant differences between the efficacy of the two strategies $(28,49,50)$. This equivalence was confirmed by three meta-analyses $(64,65,67)$.

Comparisons with other HO prophylaxis methods was conducted exclusively between RT and NSAIDs (37, 39, 51, $52,54,55,58,60,63,65,66,68)$. Three studies reported the superiority of RT over indomethacin $(37,39,60)$ or acetylsalicylic acid (51). Two other studies confirmed the 
Table III. Number of patients, comparison, and main findings of meta-analyses

\begin{tabular}{|c|c|c|c|c|}
\hline Ref & Authors, year & Patients, $\mathrm{n}$ & Comparison & Main findings \\
\hline 62 & Pakos et al., 2004 & 1,143 & RT $v s$. NSAIDs & $\begin{array}{l}\text { RT was more effective than NSAIDs in preventing grade III-IV } \\
\text { HOs }(\mathrm{RR}=0.42,95 \% \mathrm{CI}=0.18-0.97) \text { or any } \mathrm{HO} \text { (RR=0.75; } 95 \% \\
\mathrm{CI}=0.37-1.71) \text {. The overall absolute risk difference for grade III-IV } \\
\text { was minimal }(-1.18 \%, 95 \% \mathrm{CI}=-2.45-0.09 \%) \text {. Preoperative RT was } \\
\text { significantly less effective than NSAIDs and the postoperative RT } \\
\text { resulted superior to NSAIDs especially with higher doses. A } \\
\text { significant dose-response relationship was found in patients treated } \\
\text { with postoperative RT }(p=0.008) \text {. }\end{array}$ \\
\hline 63 & Vavken et al., 2009 & 1,295 & RT $v s$. NSAIDs & $\begin{array}{l}\text { The pooled RR for efficacy of RT and NSAIDs in preventing HO } \\
\text { was } 0.96 \text { ( } 95 \% \text { CI=0.88-1.06) and was not dependent on the } \\
\text { surgical technique. No statistically significant difference was found } \\
\text { between RT and NSAIDs. }\end{array}$ \\
\hline 64 & Popovic et al., 2014 & 5,464 sites & $\begin{array}{l}\text { RT doses; treatment sites; } \\
\text { postoperative } v s \text {. } \\
\text { preoperative RT }\end{array}$ & $\begin{array}{l}\text { Most studies reported results after postoperative RT (61.6\%) delivered } \\
\text { as } 7 \text { Gy single-fraction. No significant relationship was observed } \\
\text { between the number of sites where HO formed and RT dose }(p=0.1) \\
\text { nor if RT was delivered before or after surgery }(p=0.1) \text {. }\end{array}$ \\
\hline 65 & $\begin{array}{l}\text { Milakovic et al., } \\
2015\end{array}$ & 1,253 sites & $\begin{array}{l}\text { Multiple fractions } v s \text {. } \\
\text { single-fraction RT; preoperative } \\
v s \text {. postoperative RT; } \\
\text { BED }>25 \text { Gy } v s . \leq 25 \text { Gy }\end{array}$ & $\begin{array}{l}\text { Multi-fractionated RT was more effective compared to single-dose } \\
\text { RT in reducing HO risk }(p=0.04) \text {. No difference between groups } \\
\text { treated with single or multiple fractions was found in terms of HO } \\
\text { progression }(p=0.34) \text { nor between BED }>25 \text { or } \leq 25 \mathrm{~Gy}(p=0.28) \text {, nor } \\
\text { between preoperative and postoperative RT }(p=0.43) \text {. }\end{array}$ \\
\hline 66 & Cai et al., 2019 & 7,769 & $\begin{array}{l}\text { Nonselective } v s \text {. selective } \\
\text { NSAIDs } v s . \text { RT } v s . \text { controls }\end{array}$ & $\begin{array}{l}\text { Prophylaxis of } \mathrm{HO} \text { appeared to be more effective with RT. In fact, } \\
\mathrm{HO} \text { rates after surgery were lower compared to nonselective } \\
\text { NSAIDs and selective NSAIDs (OR=0.50, 95\% CI=0.25-1.0; } \\
\mathrm{OR}=0.41,95 \% \mathrm{CI}=0.17-0.97 \text { ). }\end{array}$ \\
\hline 67 & Hu et al., 2021 & 1,203 & $\begin{array}{l}\text { Low } v s . \text { medium } v s . \text { high } \\
\text { BED; multiple fractions } v s \text {. } \\
\text { single-fraction RT; preoperative } \\
v s \text {. postoperative RT }\end{array}$ & $\begin{array}{l}\text { A significantly improved prevention of } \mathrm{HO} \text { progression was found } \\
\text { for the medium BED group compared with the low one }(p=0.003) \text {, } \\
\text { while no difference was observed between low and high BED groups } \\
\text { groups }(p=0.21) \text {. A multi-fractionated RT significantly reduced HO } \\
\text { progression compared to single fraction RT ( } p=0.04) \text {. No differences } \\
\text { were recorded comparing preoperative and postoperative RT } \\
(p=0.43) \text {. }\end{array}$ \\
\hline 68 & Shapira et al., 2021 & 8,653 & $\begin{array}{l}\text { RT } v s . \text { NSAIDs } v s \text {. } \\
\text { no prophylaxis; non-selective } \\
\text { NSAIDs } v \text {. COX-II } \\
\text { selective NSAIDs }\end{array}$ & $\begin{array}{l}\text { In studies on prophylactic RT, } 28.6-97.4 \% \text { of patients showed no } \\
\text { HO, with } 0.0-11.9 \% \text { severe HO. In studies on prophylactic } \\
\text { NSAIDs-based treatment, } 76.6 \%-88.9 \% \text { of patients had no HO, } \\
\text { while } 0.0 \%-1.8 \% \text { developed severe HO. Prophylactic treatment of } \\
\text { HO with NSAIDs may be more effective than RT in high-risk } \\
\text { patients after total arthroplasty of the hip. }\end{array}$ \\
\hline
\end{tabular}

BED: Biologically effective dose; CI: confidence interval; COX-II: cyclo-oxygenase 2; HO: heterotopic ossification; NSAID: non-steroidal antiinflammatory drug; OR: odds ratio; RR: risk ratio; RT: radiotherapy.

superiority of prophylactic RT over NSAIDs in general (52, 55). In contrast, one study showed the superiority of NSAIDs over RT in terms of preventing all HOs but equivalence between the two treatments in terms of grade III-IV HO (54). Finally, two meta-analyses showed the superiority of RT over NSAIDs $(62,66)$, two meta-analyses showed the two treatments to be equivalent $(58,63)$, and one meta-analysis showed the superiority of NSAIDs (68).

Only two studies provided information on different outcomes of prophylactic RT in different HO subgroups. Ebinger et al. compared the outcome after surgery and prophylactic RT in patients with hip HO that developed after brain injury, local hip trauma, or the combination of both
(25). The authors recorded similar recurrence rates among groups, but better clinical outcome in patients with hip trauma. Cipriano et al. reported a lack of protective effect by prophylactic RT $(1 \times 7$ Gy) in patients with resected neurogenic HO (36).

In terms of surgical outcome and side-effects, one study showed that prophylactic RT combined with indomethacin did not have an impact on the stability of cementless cups (35). Moreover, another article reported prophylactic RT to be associated with delayed wound-healing rates similar to those after surgery alone (36). Furthermore, one study showed the same rate of implant loosening after prophylactic RT or indomethacin (45). In contrast, another analysis 

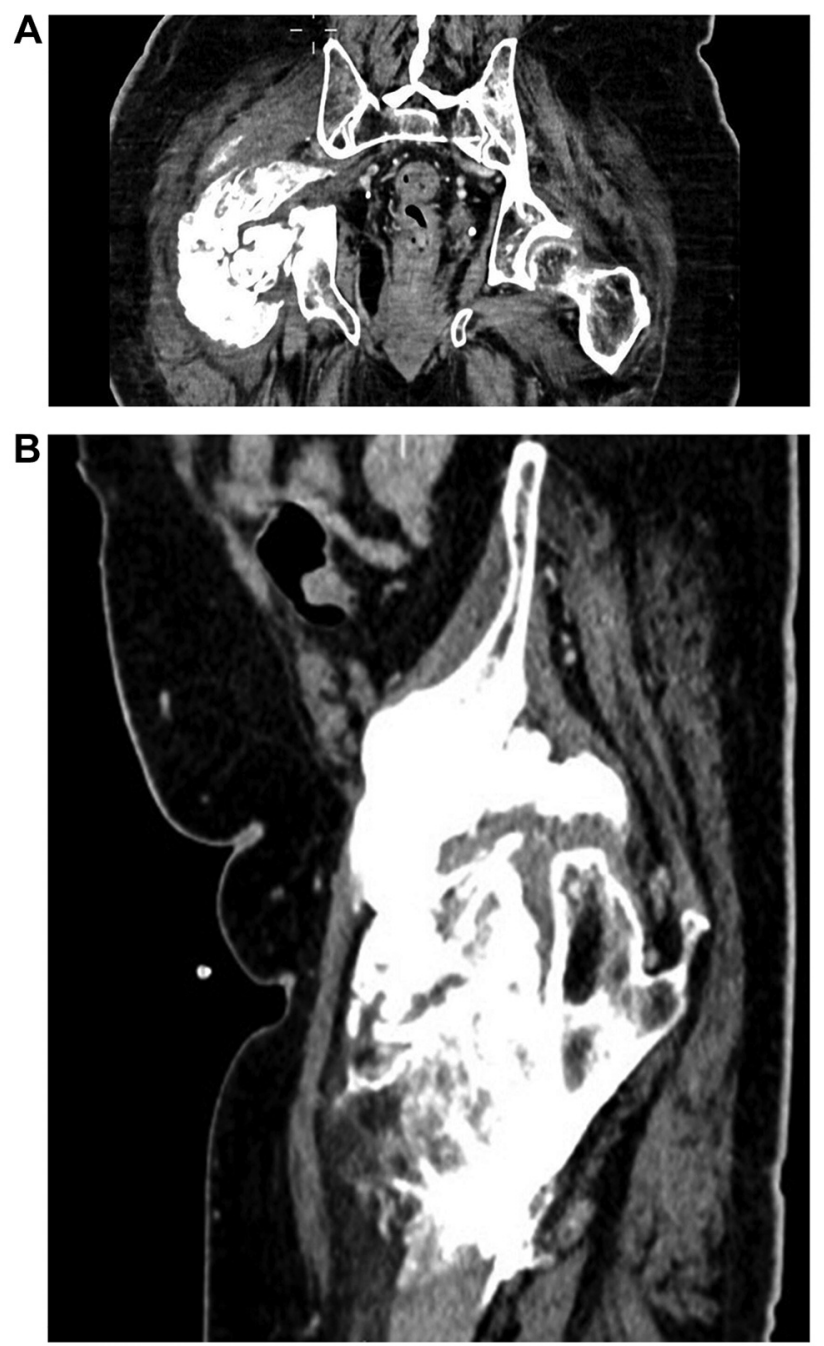

Figure 1. Extensive heterotopic ossification of the right hip in a 55-yearold male patient with paralysis of the lower extremity. Computerized tomography: A: coronal reconstruction; B: sagittal reconstruction.

showed a higher incidence of postoperative sepsis in patients undergoing prophylactic RT (44). Finally, one study showed the absence of radiation-induced toxicity in patients undergoing prophylactic RT (36) and another reported the absence of RT-induced tumors at the treated site after 10 years of follow-up (45).

In terms of RT technique, one study showed that incorrect positioning of shielding blocks is associated with a higher incidence of HO (17). Another study showed that shielding was associated with higher rates of HO (34). Finally, a planning study on patients treated with prophylactic RT reported lower mean and maximum doses to testicles in patients whose therapy was planned with a split-beam technique (42).
In summary, the results of this literature review show that $\mathrm{RT}$ is effective in the prevention of hip $\mathrm{HO}$, albeit with wide ranges of efficacy across series. Low RT doses (4-5.5 Gy) seem to be less effective compared to intermediate doses (7$8 \mathrm{~Gy}$ ), while higher doses do not provide further advantages. However, we can note that German guidelines recommend a $5 \times 3.5$ Gy regimen in patients with a high risk of developing HO (2). For effective prophylactic RT, it is important to respect the correct intervals between preoperative RT and surgery or between surgery and postoperative RT, and a careful definition of treatment fields is needed. On the contrary, clear evidence of the superiority of post-operative versus pre-operative RT is lacking. However, some authors suggested the use of pre-operative RT in order to reduce logistical problems (31) and discomfort and possible complications of post-operative RT (50).

Comparisons between prophylactic RT and administration of NSAIDs have shown conflicting results, although most evidence is in favor of RT. Furthermore, there is very little evidence on the efficacy of RT in the prevention of $\mathrm{HO}$ recurrence in patients undergoing $\mathrm{HO}$ removal and on the efficacy of RT in the different HO subgroups based on etiology. Moreover, RT is not correlated with clinically detectable side-effects, peri- or post-operative complications, or radiation-induced tumor rates.

This analysis has several limitations. Most of the evidence comes from retrospective studies. This type of study design is obviously associated with the risk of selection bias. Indeed, some authors explicitly admitted that patients at higher risk of $\mathrm{HO}$ were preferentially referred to RT over observation or drug treatment alone $(26,36)$. It is clear that this bias may have limited the detection of benefits in patients undergoing RT. In addition, many studies evaluated the incidence of HO based on the Brooker classification (69), a widely used quantitative and qualitative assessment tool. However, this classification presents some ambiguities that may limit its generalizability between different centers and specialists (70). Furthermore, no study included patientreported outcome measures among the main objectives of the analysis. Therefore, there is a lack of data on the real impact of RT on quality of life. Finally, in most cases, the evaluation of prophylactic RT efficacy was performed considering all HO grades. However, only higher-grade HOs are known to affect physical functions (30).

In conclusion, after 40 years of experience, RT is an established prophylactic treatment for hip HO. However, optimal doses, techniques, and timing remain undefined, as does the usefulness of combining RT with drug treatments, at least for some categories of patients.

Therefore, further studies are needed, in particular to i) evaluate the efficacy of RT in secondary HO prevention in combination with the resection of already developed HOs; ii) evaluate the effectiveness of RT in different $\mathrm{HO}$ 
subgroups based on etiology; iii) define optimal RT timing, technique, combinations with drugs, and dose to achieve the best therapeutic results, according to the risk categories.

\section{Conflicts of Interest}

None declared.

\section{Authors' Contributions}

AGM and MDP had the idea for the article; EG, CG, MB, and SC performed the literature search and data collection; EG, CG, MB, and AGM drafted the article; all Authors critically revised the work.

\section{References}

1 Vanden Bossche $\mathrm{L}$ and Vanderstraeten G: Heterotopic ossification: a review. J Rehabil Med 37(3): 129-136, 2005. PMID: 16040468. DOI: 10.1080/16501970510027628

2 Reinartz G, Eich HT, Pohl F and German Cooperative Group on Radiotherapy for Benign Diseases (GCG-BD): DEGRO practical guidelines for the radiotherapy of non-malignant disorders - Part IV: Symptomatic functional disorders. Strahlenther Onkol 191(4): 295-302, 2015. PMID: 25487694. DOI: 10.1007/s00066014-0789-8

3 Dey D, Wheatley BM, Cholok D, Agarwal S, Yu PB, Levi B and Davis TA: The traumatic bone: trauma-induced heterotopic ossification. Transl Res 186: 95-111, 2017. PMID: 28668522. DOI: 10.1016/j.trsl.2017.06.004

4 Baird EO and Kang QK: Prophylaxis of heterotopic ossification - an updated review. J Orthop Surg Res 4: 12, 2009. PMID: 19379483. DOI: $10.1186 / 1749-799 X-4-12$

5 Bueno TSP, Godoy GP, Furukava RB, Gaggioli NT, Tamaoki MJS, Matsunaga FT and Belloti JC: Heterotopic ossification in acetabular fractures: systematic review and meta-analysis of prophylaxis. Acta Ortop Bras 29(6): 331-340, 2021. PMID: 34849100. DOI: 10.1590/1413-785220212906244689

6 Hu X, Sun Z, Li F, Jiang C, Yan W and Sun Y: Burn-induced heterotopic ossification from incidence to therapy: key signaling pathways underlying ectopic bone formation. Cell Mol Biol Lett 26(1): 34, 2021. PMID: 34315404. DOI: 10.1186/s11658-02100277-6

7 Haffer H, Müller M, Ascherl R, Perka C and Winkler T: Diclofenac for prophylaxis of heterotopic ossification after hip arthroplasty: a systematic review. Hip Int: 1120700020978194 , 2020. PMID: 33272062 . DOI: 10.1177/1120700020978194

8 Oberberg S, Nottenkämper J, Heukamp M, Krapp J and Willburger RE: Etoricoxib is safe and effective in preventing heterotopic ossification after primary total hip arthroplasty. J Orthop Surg Res 16(1): 163, 2021. PMID: 33639986. DOI: 10.1186/s13018-021-02297-6

9 Migliorini F, Trivellas A, Eschweiler J, Driessen A, Tingart M and Maffulli N: NSAIDs for prophylaxis for heterotopic ossification after total hip arthroplasty: a Bayesian network meta-analysis. Calcif Tissue Int 108(2): 196-206, 2021. PMID: 33044630. DOI: 10.1007/s00223-020-00763-7

10 Zhang Z, Zhang Y, Wang Z, Qiu X and Chen Y: Incidence of and risk factors for the development of asymptomatic heterotopic ossification after elbow fracture fixation. J Int Med
Res 48(2): 300060519877324, 2020. PMID: 31566088. DOI: 10.1177/0300060519877324

11 Meyers C, Lisiecki J, Miller S, Levin A, Fayad L, Ding C, Sono T, McCarthy E, Levi B and James AW: Heterotopic ossification: a comprehensive review. JBMR Plus 3(4): e10172, 2019. PMID: 31044187. DOI: $10.1002 / \mathrm{jbm} 4.10172$

12 Ahrengart L: Periarticular heterotopic ossification after total hip arthroplasty. Risk factors and consequences. Clin Orthop Relat Res (263): 49-58, 1991. PMID: 1899637.

13 Łęgosz P, Otworowski M, Sibilska A, Starszak K, Kotrych D, Kwapisz A and Synder M: Heterotopic ossification: a challenging complication of total hip arthroplasty: risk factors, diagnosis, prophylaxis, and treatment. Biomed Res Int 2019: 3860142, 2019. PMID: 31119167. DOI: 10.1155/2019/3860142

14 Eggli S and Woo A: Risk factors for heterotopic ossification in total hip arthroplasty. Arch Orthop Trauma Surg 121(9): 531535, 2001. PMID: 11599757. DOI: 10.1007/s004020100287

15 Chao ST, Joyce MJ and Suh JH: Treatment of heterotopic ossification. Orthopedics 30(6): 457-64; quiz 465-6, 2007. PMID: 17598490. DOI: 10.3928/01477447-20070601-18

16 Coventry $\mathrm{MB}$ and Scanlon $\mathrm{PW}$ : The use of radiation to discourage ectopic bone. A nine-year study in surgery about the hip. J Bone Joint Surg Am 63(2): 201-208, 1981. PMID: 6780568.

17 Sylvester JE, Blount LH and Selch MT: Technical considerations in the use of prophylactic radiation therapy to prevent heterotopic bone formation. Semin Arthroplasty 3(3): 167-171, 1992. PMID: 10147775.

18 Moed BR and Letournel E: Low-dose irradiation and indomethacin prevent heterotopic ossification after acetabular fracture surgery. J Bone Joint Surg Br 76(6): 895-900, 1994. PMID: 7983114.

19 Fingeroth RJ and Ahmed AQ: Single dose 6 Gy prophylaxis for heterotopic ossification after total hip arthroplasty. Clin Orthop Relat Res (317): 131-140, 1995. PMID: 7671467.

20 Healy WL, Lo TC, DeSimone AA, Rask B and Pfeifer BA: Single-dose irradiation for the prevention of heterotopic ossification after total hip arthroplasty. A comparison of doses of five hundred and fifty and seven hundred centigray. J Bone Joint Surg Am 77(4): 590-595, 1995. PMID: 7713977. DOI: 10.2106/00004623-199504000-00013

21 Linclau L, Dokter G, Debois JM and Gutwirth P: The influence of radiation therapy on the Harris hip score in cementless total hip arthroplasty. Acta Orthop Belg 61(1): 48-52, 1995. PMID: 7725906.

22 Sudanese A, Tabarroni M, Busanelli L, Testoni M, Toni A, Spagnolli MF, Fanton F, Brizio L and Giunti A: The use of cobalt therapy to prevent heterotopic ossification after total hip arthroplasty. Chir Organi Mov 81(2): 89-106, 1996. PMID: 8968113.

23 Busanelli L, Sudanese A, Testoni M, Tabarroni M, Fanton F, Spagnolli MF, Toni A and Giunti A: Preventive cobalt therapy in heterotopic ossification consequent to prosthetic hip reimplantation. Chir Organi Mov 84(2): 135-143, 1999. PMID: 11569072.

24 Haas ML, Kennedy AS, Copeland CC, Ames JW, Scarboro M and Slawson RG: Utility of radiation in the prevention of heterotopic ossification following repair of traumatic acetabular fracture. Int J Radiat Oncol Biol Phys 45(2): 461-466, 1999. PMID: 10487572. DOI: 10.1016/s0360-3016(99)00191-1 
25 Ebinger T, Roesch M, Kiefer H, Kinzl L and Schulte M: Influence of etiology in heterotopic bone formation of the hip. J Trauma 48(6): 1058-1062, 2000. PMID: 10866251. DOI: 10.1097/00005373-200006000-00010

26 D'Lima DD, Venn-Watson EJ, Tripuraneni P and Colwell CW: Indomethacin versus radiation therapy for heterotopic ossification after hip arthroplasty. Orthopedics 24(12): 11391143, 2001. PMID: 11770090.

27 Lonardi F, Gioga G, Coeli M, Ruffo P, Agus G, Pizzoli A and Campostrini F: Preoperative, single-fraction irradiation for prophylaxis of heterotopic ossification after total hip arthroplasty. Int Orthop 25(6): 371-374, 2001. PMID: 11820444. DOI: $10.1007 / \mathrm{s} 002640100281$

28 Seegenschmiedt MH, Makoski HB, Micke O and German Cooperative Group on Radiotherapy for Benign Diseases: Radiation prophylaxis for heterotopic ossification about the hip joint - a multicenter study. Int J Radiat Oncol Biol Phys 51(3): 756-765, 2001. PMID: 11697322. DOI: 10.1016/s03603016(01)01640-6

29 Koelbl O, Seufert J, Pohl F, Tauscher A, Lehmann H, Springorum HW and Flentje M: Preoperative irradiation for prevention of heterotopic ossification following prosthetic total hip replacement results of a prospective study in 462 hips. Strahlenther Onkol 179(11): 767-773, 2003. PMID: 14605747. DOI: $10.1007 / \mathrm{s} 00066-003-1088-y$

30 Pohl F, Seufert J, Tauscher A, Lehmann H, Springorum HW, Flentje $\mathrm{M}$ and Koelbl $\mathrm{O}$ : The influence of heterotopic ossification on functional status of hip joint following total hip arthroplasty. Strahlenther Onkol 181(8): 529-533, 2005. PMID: 16044221. DOI: $10.1007 / \mathrm{s} 00066-005-1352-4$

31 Roth A, Füller J, Fährmann M, Anders J, Sachse A, Sander K and Venbrocks R: Prophylaxis of heterotopic bone formation by radiotherapy - a comparison between pre- and postsurgical activity. Acta Chir Orthop Traumatol Cech 72(1): 38-41, 2005. PMID: 15860151

32 Chao ST, Lee SY, Borden LS, Joyce MJ, Krebs VE and Suh JH: External beam radiation helps prevent heterotopic bone formation in patients with a history of heterotopic ossification J Arthroplasty 21(5): 731-736, 2006. PMID: 16877161. DOI: 10.1016/j.arth.2005.08.014

33 Pakos EE, Pitouli EJ, Tsekeris PG, Papathanasopoulou V, Stafilas $\mathrm{K}$ and Xenakis TH: Prevention of heterotopic ossification in high-risk patients with total hip arthroplasty: the experience of a combined therapeutic protocol. Int Orthop 30(2): 79-83, 2006. PMID: 16482442. DOI: 10.1007/s00264-005-0054-y

34 Balboni TA, Gaccione P, Gobezie R and Mamon HJ: Shielding of the hip prosthesis during radiation therapy for heterotopic ossification is associated with increased failure of prophylaxis Int J Radiat Oncol Biol Phys 67(5): 1499-1505, 2007. PMID: 17234358. DOI: 10.1016/j.ijrobp.2006.11.007

35 Ince A, Sauer U, Wollmerstedt N and Hendrich C: No migration of acetabular cups after prophylaxis for heterotopic ossification. Clin Orthop Relat Res 461: 125-129, 2007. PMID: 17415004. DOI: $10.1097 /$ BLO.0b013e31805c0d82

36 Cipriano C, Pill SG, Rosenstock J and Keenan MA: Radiation therapy for preventing recurrence of neurogenic heterotopic ossification. Orthopedics 32(9): 42854, 2009. PMID: 19750999. DOI: $10.3928 / 01477447-20090728-33$

37 Pakos EE, Stafilas KS, Politis AN, Tsekeris PG, Mitsionis G and Xenakis TA: Heterotopic ossification after total hip arthroplasty
(THA) in congenital hip disease: comparison of two different prophylactic protocols. Clin Transl Oncol 11(2): 103-108, 2009. PMID: 19211376. DOI: 10.1007/s12094-009-0322-1

38 Pakos EE, Tsekeris PG, Paschos NK, Pitouli EJ, Motsis EK and Xenakis TA: The role of radiation dose in a combined therapeutic protocol for the prevention of heterotopic ossification after total hip replacement. J BUON 15(1): 74-78, 2010. PMID: 20414931.

39 Le Duff MJ, Takamura KB and Amstutz HC: Incidence of heterotopic ossification and effects of various prophylactic methods after hip resurfacing. Bull NYU Hosp Jt Dis 69 Suppl 1: S36-S41, 2011. PMID: 22035483.

40 Weng HK, Wu PK, Chen CF, Chung LH, Liu CL, Chen TH and Chen WM: Total hip arthroplasty for patients who have ankylosing spondylitis: is postoperative irradiation required for prophylaxis of heterotopic ossification? J Arthroplasty 30(10): 1752-1756, 2015. PMID: 25980776. DOI: 10.1016/j.arth. 2015.04.022

41 d'Heurle A, Archdeacon MT, Hiratzka S, Casstevens C, Finnan $\mathrm{R}$ and McCoy B: Do surrogates of injury severity influence the occurrence of heterotopic ossification in fractures of the acetabulum? J Orthop Trauma 30(4): 213-216, 2016. PMID: 26606599. DOI: 10.1097/BOT.0000000000000490

42 Mourad WF, Ma JK, Packianathan S, Yan W, Shaaban SG, Marchan EM, Abdallah LE, He R, Mobit PN, Yang CC and Vijayakumar S: Testicular dose during prophylaxis of heterotopic ossification with radiation therapy. In Vivo 31(3): 461-466, 2017. PMID: 28438880. DOI: 10.21873/invivo.11084

43 Müseler AC, Grasmücke D, Jansen O, Aach M, Meindl R, Schildhauer TA and Citak M: In-hospital outcomes following single-dose radiation therapy in the treatment of heterotopic ossification of the hip following spinal cord injury-an analysis of 444 cases. Spinal Cord 55(3): 244-246, 2017. PMID: 27431658. DOI: $10.1038 / \mathrm{sc} .2016 .112$

44 Honore T, Bonan I, Salga M, Denormandie P, Labib A, Genet G, Grelier A and Genet F: Effectiveness of radiotherapy to prevent recurrence of heterotopic ossification in patients with spinal cord injury and traumatic head injury: A retrospective case-controlled study. J Rehabil Med 52(5): jrm00066, 2020. PMID: 32421202. DOI: $10.2340 / 16501977-2692$

45 Pakos EE, Papadopoulos DV, Gelalis ID, Tsantes AG, Gkiatas I, Kosmas D, Tsekeris PG and Xenakis TA: Is prophylaxis for heterotopic ossification with radiation therapy after THR associated with early loosening or carcinogenesis? Hip Int 30(5): 559-563, 2020. PMID: 30990093. DOI: 10.1177/1120700019842724

46 Konski A, Pellegrini V, Poulter C, DeVanny J, Rosier R, Evarts $\mathrm{CM}$, Henzler $\mathrm{M}$ and Rubin P: Randomized trial comparing single dose versus fractionated irradiation for prevention of heterotopic bone: a preliminary report. Int J Radiat Oncol Biol Phys 18(5): 1139-1142, 1990. PMID: 2112120. DOI: 10.1016/ 0360-3016(90)90450-x

47 Seegenschmiedt MH, Goldmann AR, Wölfel R, Hohmann D, Beck H and Sauer R: Prevention of heterotopic ossification (HO) after total hip replacement: randomized high versus low dose radiotherapy. Radiother Oncol 26(3): 271-274, 1993. PMID: 8316658. DOI: $10.1016 / 0167-8140(93) 90270-\mathrm{i}$

48 Seegenschmiedt MH, Goldmann AR, Martus P, Wölfel R, Hohmann D and Sauer R: Prophylactic radiation therapy for prevention of heterotopic ossification after hip arthroplasty: results in 141 high-risk hips. Radiology 188(1): 257-264, 1993. PMID: 8511308. DOI: 10.1148/radiology.188.1.8511308 
49 Gregoritch SJ, Chadha M, Pelligrini VD, Rubin P and Kantorowitz DA: Randomized trial comparing preoperative versus postoperative irradiation for prevention of heterotopic ossification following prosthetic total hip replacement: preliminary results. Int J Radiat Oncol Biol Phys 30(1): 55-62, 1994. PMID: 8083129. DOI: 10.1016/0360-3016(94)90519-3

50 Pellegrini VD Jr and Gregoritch SJ: Preoperative irradiation for prevention of heterotopic ossification following total hip arthroplasty. J Bone Joint Surg Am 78(6): 870-881, 1996. PMID: 8666605. DOI: 10.2106/00004623-199606000-00010

51 Knelles D, Barthel T, Karrer A, Kraus U, Eulert J and Kölbl O: Prevention of heterotopic ossification after total hip replacement. A prospective, randomised study using acetylsalicylic acid, indomethacin and fractional or single-dose irradiation. J Bone Joint Surg Br 79(4): 596-602, 1997. PMID: 9250745. DOI: 10.1302/0301-620x.79b4.6829

52 Kölbl O, Knelles D, Barthel T, Kraus U, Flentje M and Eulert J: Randomized trial comparing early postoperative irradiation $v s$. the use of nonsteroidal antiinflammatory drugs for prevention of heterotopic ossification following prosthetic total hip replacement. Int J Radiat Oncol Biol Phys 39(5): 961-966, 1997. PMID: 9392532. DOI: 10.1016/s0360-3016(97)00496-3

53 Seegenschmiedt MH, Keilholz L, Martus P, Goldmann A, Wölfel R, Henning F and Sauer R: Prevention of heterotopic ossification about the hip: final results of two randomized trials in 410 patients using either preoperative or postoperative radiation therapy. Int J Radiat Oncol Biol Phys 39(1): 161171, 1997. PMID: 9300751. DOI: 10.1016/s0360-3016(97) 00285-x

54 Kölbl O, Knelles D, Barthel T, Raunecker F, Flentje M and Eulert J: Preoperative irradiation versus the use of nonsteroidal anti-inflammatory drugs for prevention of heterotopic ossification following total hip replacement: the results of a randomized trial. Int J Radiat Oncol Biol Phys 42(2): 397-401, 1998. PMID: 9788422. DOI: 10.1016/s0360-3016(98)00204-1

55 Sell S, Willms R, Jany R, Esenwein S, Gaissmaier C, Martini F, Bruhn G, Burkhardsmaier F, Bamberg M and Küsswetter W: The suppression of heterotopic ossifications: radiation versus NSAID therapy - a prospective study. J Arthroplasty 13(8): 854-859, 1998. PMID: 9880175. DOI: 10.1016/s0883-5403(98)90189-9

56 van Leeuwen WM, Deckers P and de Lange WJ: Preoperative irradiation for prophylaxis of ectopic ossification after hip arthroplasty. A randomized study in 62 hips. Acta Orthop Scand 69(2): 116-118, 1998. PMID: 9602765. DOI: 10.3109/ 17453679809117609

57 Kienapfel H, Koller M, Wüst A, Sprey C, Merte H, EngenhartCabillic R and Griss P: Prevention of heterotopic bone formation after total hip arthroplasty: a prospective randomised study comparing postoperative radiation therapy with indomethacin medication. Arch Orthop Trauma Surg 119(5-6): 296-302, 1999. PMID: 10447627. DOI: 10.1007/s004020050414

58 Burd TA, Lowry KJ and Anglen JO: Indomethacin compared with localized irradiation for the prevention of heterotopic ossification following surgical treatment of acetabular fractures. J Bone Joint Surg Am 83(12): 1783-1788, 2001. PMID: 11741055. DOI: $10.2106 / 00004623-200112000-00003$

59 Padgett DE, Holley KG, Cummings M, Rosenberg AG, Sumner DR, Conterato D and Galante JO: The efficacy of 500 CentiGray radiation in the prevention of heterotopic ossification after total hip arthroplasty: a prospective, randomized, pilot study. J
Arthroplasty 18(6): 677-686, 2003. PMID: 14513439. DOI: 10.1016/s0883-5403(03)00265-1

60 Pakos EE, Stafilas KS, Tsekeris PG, Politis AN, Mitsionis G and Xenakis TA: Combined radiotherapy and indomethacin for the prevention of heterotopic ossification after total hip arthroplasty. Strahlenther Onkol 185(8): 500-505, 2009. PMID: 19652932. DOI: $10.1007 / \mathrm{s} 00066-009-1954-3$

61 Liu JZ, Frisch NB, Barden RM, Rosenberg AG, Silverton CD and Galante JO: Heterotopic ossification prophylaxis after total hip arthroplasty: randomized trial of 400 vs 700 cGy. J Arthroplasty 32(4): 1328-1334, 2017. PMID: 27884418. DOI: 10.1016/j.arth.2016.10.030

62 Pakos EE and Ioannidis JP: Radiotherapy $v s$. nonsteroidal antiinflammatory drugs for the prevention of heterotopic ossification after major hip procedures: a meta-analysis of randomized trials. Int J Radiat Oncol Biol Phys 60(3): 888-895, 2004. PMID: 15465207. DOI: 10.1016/j.ijrobp.2003.11.015

63 Vavken P, Castellani L and Sculco TP: Prophylaxis of heterotopic ossification of the hip: systematic review and metaanalysis. Clin Orthop Relat Res 467(12): 3283-3289, 2009. PMID: 19517202. DOI: 10.1007/s11999-009-0924-5

64 Popovic M, Agarwal A, Zhang L, Yip C, Kreder HJ, Nousiainen MT, Jenkinson R, Tsao M, Lam H, Milakovic M, Wong E and Chow E: Radiotherapy for the prophylaxis of heterotopic ossification: a systematic review and meta-analysis of published data. Radiother Oncol 113(1): 10-17, 2014. PMID: 25220370. DOI: $10.1016 /$ j.radonc.2014.08.025

65 Milakovic M, Popovic M, Raman S, Tsao M, Lam H and Chow E: Radiotherapy for the prophylaxis of heterotopic ossification: A systematic review and meta-analysis of randomized controlled trials. Radiother Oncol 116(1): 4-9, 2015. PMID: 26163090. DOI: $10.1016 /$ j.radonc.2015.05.022

66 Cai L, Wang Z, Luo X, She W and Zhang H: Optimal strategies for the prevention of heterotopic ossification after total hip arthroplasty: A network meta-analysis. Int J Surg 62: 74-85, 2019. PMID: 30615954. DOI: 10.1016/j.ijsu.2018.12.011

$67 \mathrm{Hu}$ ZH, Chen W, Sun JN, Zhang Y, Zhang Y, Chen XY and Feng $\mathrm{S}$ : Radiotherapy for the prophylaxis of heterotopic ossification after total hip arthroplasty: A systematic review and meta-analysis of randomized controlled trails. Med Dosim 46(1): 65-73, 2021. PMID: 32928622. DOI: 10.1016/j.meddos.2020.07.010

68 Shapira J, Yelton MJ, Chen JW, Rosinsky PJ, Maldonado DR, Meghpara M, Lall AC and Domb BG: Efficacy of NSAIDs versus radiotherapy for heterotopic ossification prophylaxis following total hip arthroplasty in high-risk patients: a systematic review and meta-analysis. Hip Int: 1120700021991115, 2021. PMID: 33736491. DOI: $10.1177 / 1120700021991115$

69 Hug KT, Alton TB and Gee AO: Classifications in brief: Brooker classification of heterotopic ossification after total hip arthroplasty. Clin Orthop Relat Res 473(6): 2154-2157, 2015. PMID: 25427427. DOI: 10.1007/s11999-014-4076-x

70 Tao MJ, Probyn L, Poon M, Kreder H, Nousiainen M, Jenkinson R, Wan Bo A, Tsao M, Barnes E and Chow E: Potential discrepancy between plain films and $\mathrm{CT}$ scans in Brooker classification of heterotopic ossification. $\mathrm{Br} \mathrm{J}$ Radiol 90: 20170263, 2017. PMID: 28972793. DOI: 10.1259/bjr.20170263

Received January 4, 2022

Revised February 4, 2022

Accepted February 7, 2022 